\title{
PENGARUH CITRA MEREK, PERSEPSI HARGA DAN KUALITAS PRODUK HONDA BRIO SATYA TERHADAP MINAT BELI PELANGGAN DI JAKARTA
}

\author{
Dimas Rizky A \\ Program Studi Magister Manajemen Universitas Tarumanagara \\ rizkydimasanugrah@gmail.com \\ Carunia Mulya Firdausy \\ Program Studi Magister Manajemen Universitas Tarumanagara
}

Masuk : 07-12-2019, revisi : 20-12-2019 diterima untuk diterbitkan : 21-12-2019

\begin{abstract}
The purpose of this study is to examine the effects of brand image, perceive price and product quality on purchase intention. The number of samples in this study was 160 respondents consisting of potential customers and the customers Honda Brio Satya of PT. Honda Prospect Motor in Jakarta. The technique to sampling unit analysis was convenience nonprobality sampling method. The results of this study as follow. First, it was found that brand image has a positive and significant effect on purchase intention. Second, perceive price has a positive and significant effect on purchase intention. Third, product quality has a positive effect on purchase intention. Fourth, brand image, price perception and product quality jointlyl effect purchase intention of Honda Brio customer. Therefore, to improve the purchase intention of the customers, the company should give a great concern to brand image, price and the quality of Honda car production.
\end{abstract}

Keywords : Brand Image; Perception Price; Product Quality; Purchase Intention

Abstrak : Tujuan dari penelitian ini adalah untuk menguji pengaruh citra merek, persepsi harga dan kualitas produk terhadap niat beli. Jumlah sampel dalam penelitian ini adalah 160 responden yang terdiri dari pelanggan potensial dan pelanggan Honda Brio Satya dari PT. Honda Prospect Motor di Jakarta. Teknik analisis unit sampling adalah metode convenience nonprobality sampling. Hasil penelitian ini sebagai berikut. Pertama, ditemukan bahwa citra merek memiliki pengaruh positif dan signifikan terhadap niat beli. Kedua, harga persepsi memiliki pengaruh positif dan signifikan terhadap niat beli. Ketiga, kualitas produk berpengaruh positif terhadap niat beli. Keempat, citra merek, persepsi harga, dan kualitas produk secara bersama-sama memengaruhi niat beli pelanggan Honda Brio. Oleh karena itu, untuk meningkatkan niat beli pelanggan, perusahaan harus memberikan perhatian besar pada citra merek, harga, dan kualitas produksi mobil Honda.

Kata Kunci : Citra Merek; Persepsi Harga; Kualitas Produk; Minat Beli

\section{PENDAHULUAN}

Industri otomotif khususnya industri mobil berkembang sangat pesat di Indonesia sehingga membuat tingkat persaingan menjadi semakin ketat diantara produsen mobil. Para Agen Tunggal Pemegang Merek (ATMP) terus melakukan pengembangan pada produknya. Hal ini terlihat jelas bahwa saat ini semakin beraneka ragamnya tipe kendaraan yang dihadirkan oleh produsen mobil. Salah satu produsen mobil seperti Honda yang memiliki 11 line up kendaraan untuk kelas ekonomi bawah hingga kelas ekonomi atas. Akibatnya, konsumen semakin selektif dalam memilih mobil yang akan dibelinya sesuai dengan kebutuhan dari konsumen itu sendiri. 
Perkembangan segmen mobil LCGC di Indonesia sudah terlihat sejak awal tahun 2012an ketika pemerintah mengeluarkan peraturan mengenai mobil LCGC yang kemudian ditandai dengan hadirnya Toyota Agya, Honda Brio Satya, Daihatsu Ayla hingga Suzuki Wagoon. Berdasarkan data GAIKINDO sepanjang Januari - November 2017, segmen LCGC menghasilkan pangsa pasar yang besar karena berhasil menyumbang penjualan mencapai 234.554 unit atau sekitar 23,5\% dari total 994.436 unit kendaraan roda empat yang terjual di Indonesia (Gaikindo, 2018).

Banyaknya pilihan konsumen pada segmen LCGC membuat PT Honda Prospect Motor sebagai produsen mobil LCGC dengan merek Honda Brio Satya harus memiliki strategi pemasaran khusus dalam upaya meningkatkan minat beli produknya. Diantara beragam faktor yang mempengaruhi minat beli, terdapat beberapa faktor yang dianggap sangat mempengaruhi konsumen dalam meningkatkan minat beli mereka yakni citra merek dan kualitas produk serta harga. Ketiga faktor ini secara empiric telah diteliti memengaruhi minat beli terhadap suatu produk (lihat, misalnya, Wang dan Tsai, 2014, Schiffman dan Kanuk, 2007).

Oleh karena itu, penelitian ini bertujuan untuk menganalisis pengaruh citra merek, persepsi harga dan kualitas produk terhadap minat beli mobil Honda Brio Satya pada PT. Honda Motor di Jakarta. Dengan adanya penelitian ini diharapkan perusahaan dapat meningkatkan strateginya dalam pengembangan produk dan strategi pemasarannya.

\section{LANDASAN TEORI DAN HIPOTESIS}

Seperti diungkapkan dalam pendahuluan bahwa telah banyak penelitian yang mengkaji pengaruh citra merek, harga dan kualitas produk terhadap minat beli suatu produk. Tjiptono (2011:112), misalnya, menemukan bahwa bahwa citra merek memberikan pengaruh pada minat beli konsumen. Hal ini karena citra merek merupakan deskripsi persepsi mengenai nilainilai yang terkandung dalam suatu merek dan diyakini dalam benak konsumen.

Demikian pula dengan penelitian yang dilakukan Wang dan Tsai (2014). Hasil penelitian ini mengungkapkan bahwa terdapat pengaruh positif dari citra merek (brand image) terhadap minat beli (purchase intention). Brand image yang dibangun dengan baik mampu menimbulkan perceived value yang positif di mata investor sehingga mampu meningkatkan purchase intention para investor. Penelitian tersebut juga didukung oleh Lin dan Lin (2007) yang menyatakan bahwa purchase intention konsumen dipengaruhi oleh brand image. Semakin tinggi status brand image, semakin tinggi pula purchase intention konsumen.

Dalam hal persepsi harga, Wang dan Chen (2016) menunjukkan bahwa persepsi harga secara signifikan berpengaruh langsung terhadap minat beli konsumen, persepsi harga yang dirasakan konsumen tidak hanya dapat meningkatkan niat pembelian konsumen secara langsung, tetapi juga meningkatkan nilai yang dirasakan konsumen dan menurunkan risiko yang dirasakan, yang pada ahirnya dapat merangsang niat beli konsumen. Sementara penelitian yang dilakukan oleh Jaafar, Lalp, dan Naba (2012) menunjukkan bahwa persepsi harga berpengaruh positif terhadap minat pembelian.

Selain penelitian di atas, Mirabi, Akbariyeh, dan Tahmasebifard (2015) menunjukkan kualitas produk berpengaruh positif terhadap minat beli konsumen. Penelitian tersebut didukung oleh penelitian sebelumnya yang dilakukan oleh Chi, Yeh \& Huang (2013) yang menyimpulkan bahwa jika suatu produk memiliki kualitas yang lebih baik, pelanggan akan lebih cenderung untuk membelinya.

Berdasarkan hasil penelitian di atas, studi ini ditujukan untuk mengkaji apakah ketiga variable brand image, persepsi harga dan kualitas produk juga memengaruhi minat beli konsumen khsusunya untuk produk Honda Brio. Hipotesis dari penelitian ini sebagai berikut. H1 : Terdapat pengaruh positif antara citra merek terhadap minat beli mobil Honda Brio Satya di Jakarta.

H2 : Terdapat pengaruh positif antara persepsi harga terhadap minat beli mobil Honda Brio Satya di Jakarta. 
H3 : Terdapat pengaruh positif antara kualitas produk terhadap minat beli mobil Honda Brio Satya di Jakarta.

H4 : Terdapat pengaruh simultan antara citra merek, persepsi harga dan kualitas produk terhadap minat beli mobil Honda Brio Satya di Jakarta.

\section{METODOLOGI PENELITIAN}

Populasi penelitian ini adalah semua pelanggan potensial dan pelanggan tetap salah satu merek kendaraan roda empat yang ada di Jakarta. Jumlah sampel penelitian ini sebesar 160 responden Wijaya (2009). Metode pengambilan sampel pada penelitian ini adalah nonprobability sampling, dengan teknik convenience sampling. Berdasarkan data yang terkumpul, karakteristik responden didominasi oleh pria $(61,3 \%)$, berusia $20-29$ tahun $(37,5 \%)$, bertempat tinggal di Jakarta Utara (25\%), pekerjaan sebagai pegawai swasta $(34,4 \%)$, jumlah anggota keluarga sebanyak 3 orang $(35,6 \%)$ dan menggunakan kendaraan pribadi selama satu bulan sebanyak lebih dari 16-25 kali dalam satu bulan $(38,4 \%)$.

Dalam memberikan pembobotan terhadap 3 variabel bebas (citra merek, persepsi harga dan kualitas produk) dan 1 variabel tidak bebas (minat beli). digunakan skala Likert dengan rentang nilai antara satu sampai lima, yaitu (1) sangat tidak setuju, (2) tidak setuju, (3) netral, (4) setuju dan (5) sangat setuju. Adapun indikator dari masing-masing variable dapat dilihat pada Tabel 1.

Tabel 1

Variabel dan Pengukuran

\begin{tabular}{|c|c|c|c|}
\hline No. & Variabel dan indikator & Jumlah Item & Sumber \\
\hline 1 & $\begin{array}{l}\text { Citra Merek (Kualitas, Sejarah, dan } \\
\text { Memperhatikan pelanggan) }\end{array}$ & 3 & $\begin{array}{l}\text { Davis et al. (2009) dan } \\
\text { Jalilvand et al. (2012) }\end{array}$ \\
\hline 2 & $\begin{array}{l}\text { Persepsi Harga (Kinerja dan Value for } \\
\text { money) }\end{array}$ & 3 & Herrmann et al. (2007) \\
\hline 3 & $\begin{array}{l}\text { Kualitas Produk } \\
\text { a) Kinerja } \\
\text { b) Fitur } \\
\text { c) Kesesuaian dengan spesifikasi } \\
\text { d) Daya Tahan } \\
\text { e) Keandalan } \\
\text { f) Kemudahan dalam perbaikan } \\
\text { g) Estetika } \\
\text { h) Persepsi Kualitas }\end{array}$ & $\begin{array}{l}3 \\
2 \\
2 \\
2 \\
3 \\
2 \\
2 \\
2 \\
\end{array}$ & Kianpour et al. (2014) \\
\hline 1 & Minat Beli & 3 & Jalilvand dan Samiei (2012) \\
\hline
\end{tabular}

Metode analisis data yang digunakan adalah analisis statistik regresi ganda. Namun sebelum analisi regresi dilakukan, pengujian validatas dan reliabilitas data dilakukan terlebih dahulu. Setelah itu dilakukan uji normalitas, uji multikolinieritas dan uji heteroskedastisitas terhadap model yang akan diestimasi. Model Regressi ganda dimaksud adalah :

$$
\mathrm{Y}=\mathrm{a}+\mathrm{b}_{1} \mathrm{X}_{1}+\mathrm{b}_{2} \mathrm{X}_{2}+\ldots . .+\mathrm{b}_{\mathrm{k}} \mathrm{X}_{\mathrm{k}}+\mathrm{e}
$$

\section{Keterangan:}

$\mathrm{Y}=$ nilai variabel dependen yang diprediksikan

a = konstanta atau bilangan harga $\mathrm{X}=0$

$\mathrm{b} \quad=$ koefisien regresi

$\mathrm{X}=$ nilai variabel dependen

e = error atau residu 


\section{HASIL DAN PEMBAHASAN}

Hasil pengujian hipotesi penelitian ini dapat dilihat pada Tabel 2. Pada Tabel 2 dapat diperhatikan bahwa citra merek, persepsi harga dan kualitas produk bepengaruh positif dan signifikan terhadap minat beli konsumen produk Honda Brio Satya PT Honda Prospect Motor khususnya di area Jakarta.

Tabel 2

Hasil Pengujian Hipotesis

\begin{tabular}{|c|c|c|c|}
\hline Hipotesis & B & Sig. & Kesimpulan \\
\hline $\mathrm{H}_{1} \begin{array}{l}\text { Terdapat pengaruh positif citra merek } \\
\text { terhadap minat beli. }\end{array}$ & 0,191 & 0,035 & Tidak Ditolak \\
\hline $\begin{array}{c}\mathrm{H}_{2} \text { Terdapat pengaruh positif persepsi harga } \\
\text { terhadap minat beli. }\end{array}$ & 0,288 & 0,001 & Tidak Ditolak \\
\hline $\begin{array}{c}\mathrm{H}_{3} \\
\begin{array}{c}\text { Terdapat pengaruh positif kualitas produk } \\
\text { terhadap minat beli. }\end{array}\end{array}$ Hipotesis & 0,108 & 0,000 & Tidak Ditolak \\
\hline $\mathrm{H}_{4} \begin{array}{c}\text { Citra merek, perspesi harga dan kualitas } \\
\text { produk secara simultan berpengaruh } \\
\text { terhadap minat beli }\end{array}$ & 55.888 & 0,000 & Kesimpulan \\
\hline
\end{tabular}

Hasil penelitian ini sesuai dengan penelitain sebelumnya yang dilakukan oleh Wang dan Tsai (2014) serta Lin dan Lin (2007) yang menunjukkan bahwa citra merek berpengaruh secara positif terhadap minat beli. Citra merek yang baik mengenai suatu produk dapat terbentuk dari setiap aktivitas promosi yang dilakukan oleh perusahaan, sehingga dapat mempengaruhi minat beli konsumen.

Untuk hipotesis yang kedua, hasil penelitian ini juga didukung oleh penelitian yang dilakukan oleh Wang dan Chen (2016), Kim et al. (2005) dan Jaafar et al. (2012) yang menunjukkan bahwa persepsi harga berpengaruh positif terhadap minat beli. Tinggi atau rendahnya persepsi harga dipengaruhi oleh nilai yang didapatkan dari suatu barang. Ketika konsumen merasakan nilai yang didapatkan dari suatu produk lebih rendah dari harga yang ditawarkan, maka konsumen cenderung menilai harga yang ditawarkan tinggi, dan begitupun sebaliknya. Pengalaman pembelian pada masa lalu juga berdampak pada persepsi harga yang terbentuk pada masa sekarang.

Demikian pula dengan kualitas produk berpengaruh positif terhadap minat beli pelanggan dimana didukung penelitian sebleumnya yang dilakukan oleh Mirabi et al. (2015), Chi et al. (2013) serta Tsiotsou (2005)yang menunjukkan bahwa kualitas produk berpengaruh positif terhadap minat beli. Kualitas produk merupakan indikator seberapa besar nilai atau manfaat produk tersebut bagi pelanggan, jika unsur-unsur kualitas pada suatu produk dirasakan sesuai dengan apa yang diinginkan konsumen dan dapat memenuhi kebutuhan konsumen, maka minat untuk membeli produk tersebut cenderung semakin besar.

Selain pengaruh parsial dari masing-masing variable, pengaruh seluruh variable bebas dalam studi ini juga didukung oleh penelitian sebelumnya. Chavan (2003) dan Grewal (1998) mendapatkan bahwa kualitas produk, persepsi harga dan citra merek memiliki pengaruh signifikan terhadap minat beli. Jika kualitas dari produk itu melebihi ekspetasi dari kebutuhan konsumen, pelanggan akan senang dan mempertimbangkan produk ini bisa diterima bahkan bermutu tinggi, tingginya kepuasan tersebut juga turut akan mempengaruhi kemungkinan terjadinya pembelian berulang. Oleh karena itu minat beli terhadap mobil Honda Brio sangat dipenagruihi oleh citra merek, perspsi harga dan kualitas produk. 


\section{KESIMPULAN DAN SARAN}

Penelitian ini bertujuan untuk mengetahui pengaruh citra merek, persepsi harga, kualitas produk terhadap minat beli pelanggan. Dari hasil analisis regersi ganda ditemukan bahwa citra merek, persepsi harga dan kulitas produk memengaruhi minat beli pelanggan mobil Honda Brio Satya yang dijual PT Honda Prospect Motor di area jakarta baik secara parsial maupun bersama-sama.

Oleh karena itu, PT Honda Prospect Motor khususnya untuk penjualan di area Jakarta hendaknya terus membangun citra merek yang positif melalui aktivitas dan media pemasaran yang sesuai dengan target pasar, menjaga standar kualitas pelayanan purna jual produk dengan baik dan menjaga kepercayaan serta hubungan yang baik kepada komunitas atau pengguna produk dengan mengadakan kegiatan acara kumpul bersama komunitas pengguna produk dari seluruh Indonesia sehingga memberikan word of mouth yang positif mengenai produk. Hal yang sama juga perlu dilakukan untuk terus mempertahankan harga yang kompetitif terhadap pesaing lainnya melalui strategi value for money dengan memberikan bonus serta promo seperti program gratis perawatan berkala selama periode tertentu maupun dalam bentuk program cash back yang diberikan secara langsung kepada calon pelanggan.

Selain itu, perusahaan juga perlu terus melakukan penyegaran serta penambahan fiturfitur produk secara berkala kepada produk agar sesuai dengan perkembangan dan kebutuhan pasar serta meningkatkan fungsi quality control agar produk yang dihasilkan sesuai dengan standar kualitas yang sudah ditentukan.

\section{DAFTAR PUSTAKA}

Chavan, R. B. (2003). Manual on Quality Assurance for Khadi. Mahatma Gandhi Institute of Rural Industrialization a Collaborative Project of KVIC \& IITD

Chi. K. H., H. R. Yeh. dan M. W. Huang. (2013). The Influences Of Advertising Endorser, Brand Image, Brand Equity, Price Promotion, On Purchase Intention The Mediating Effect Of Advertising Endorser. Journal Management, 1(1) pp: 1-10.

Grewal, D., Monroe, K.B dan Khrisnan, R. (1998). "The Effects of Price Comparison Advertising on Buyers Perception od Acquisition Value, Transaction Value, and Behavioral Intentions". Journal of Marketing, Vol. 62, pp 46

Jaafar, S.N., Lalp, P.E. \& Naba, M.M. (2012). Consumers' Perceptions, Attitudes and Purchase Intention towards Private Label Food Products in Malaysia. Asian Journal of Business and Management Sciences. Vol. 2, No.8, pp. 73- 90.

Kim HW., Sumeet G. dan Li H. (2005). Different effect of perceived risk and price on purchase intention for potential and repeat customers. Journal of Consumer Marketing, 20(4), 335351.

Kotler, Philip \& Gerry Armstrong. (2012). Principles of Marketing. Pearson Education Limited. New Jersey.

Kotler, Philip \& Gerry Armstrong. (2014). Principle of Marketing, 15th edition. New Jersey: Pearson Pretice Hall.

Lin, Nan Hong \& Lin, Bih Shya, (2007). "The Effect of Brand Image and Product Knowledge on Purchase Intention Moderated by Price Discount". Journal of International Management Studies.

Mirabi, V., Akbariyeh, H., \& Tahmasebifard, H. (2015). A Study of Factors Affecting on Customers Purchase Intention Case Study: The Agencies of Bono Brand Tile in Tehran. Journal of Multidisciplinary Engineering Science and Technology (JMEST) ISSN: 31590040 Vol. 2 Issue 1, 267- 273.

Schiffman, Leon G. dan Leslie Lazar Kanuk. (2004). Cosumer Behavior. Pearson Prentice Hall. United States of America.

Schiffman, Leon G. dan Leslie Lazar Kanuk. (2007). Perilaku Konsumen. Jakarta: Indeks.

Tjiptono, Fandy, 2011, Strategi Pemasaran, Yogyakarta: Andi. 
Tsiotsou, Rodoula, 2005. Perceived Quality Levels and Their Relation to Involvement, Satisfaction, and Purchase Intentions, Marketing Bulletin.

Wang Ya-Hui dan Chen Li-Yan. (2016). "An Empirical Study of the Effect of Perceived Price on Purchase Intention Evidence from Low-Cost Carriers". International Journal of Business and Social Science Vol. 7, No. 4.

Wang Ya-Hui dan Tsai Cing-Fen. (2014). "The relationship between brand image and purchase intention: Evidence from award winning mutual funds." The international Journal of Bussines and Finance Research Vol 8 (2) 27-39.

Wu, P.; G.Y.Y. Yeh; dan C.R. Hsiao. (2011). The effect of store image and service quality on brand image and purchase intention for private label brands, Australian Marketing Journal (AMJ) 19(1)" 30-39.

Gaikindo.com Data Market Passangger Car 2017. Diakses pada 197 April 2018, pukul 20.30 WIB dari https://www.gaikindo.or.id/ 